\title{
An exploration study to find the effect of new advertisement techniques on export based product development: A case study of mobile devices
}

\author{
Shahram Hashemi, Naser Azad* and Seyed Mohsen Seyed Ali Akbar
}

Department of Management, Islamic Azad University, South Tehran Branch, Tehran, Iran

\begin{tabular}{l}
\hline C H R O N I C L E \\
\hline Article history: \\
Received June 10, 2013 \\
Received in revised format \\
25 August 2013 \\
Accepted September 22013 \\
Available online \\
September 32013 \\
\hline Keywords: \\
Factor analysis \\
Mobile devices \\
New advertisement techniques
\end{tabular}
\begin{abstract}
A B S T R A C T
During the past few years, new methods of advertisements such as internet, email services, etc. have created new opportunities to promote products and services. The cost of an email message is normally negligible but the outcome could be significant. This paper presents an empirical investigation to find the effect of new advertisement techniques on export based product development in a case study of mobile devices. The proposed study designs a questionnaire in Likert scale consists of 29 questions, distributes it among 150 exporters of mobile devices in Iran. Cronbach alpha is calculated as 0.826. In addition, Kaiser-Meyer-Olkin Measure of Sampling Adequacy and Approx. Chi-Square are 0.790 and 1023.3, respectively. Based on the results of our survey, we have derived five factors including emotional effects, brand promises, pricing strategy, modern advertisements and detected promotions.
\end{abstract}

(C) 2013 Growing Science Ltd. All rights reserved.

\section{Introduction}

During the past few years, recent advances on information technology have significantly changed traditional advertisement systems (Lee et al., 2011). Many business owners use cyber space to penetrate into market and introduce their products and services. These days, it is possible to send an advertisement via email services or mobile short message service (SMS) virtually to hundreds of potential customers, instantly. The cost of advertisement via email or SMS is so low that many small businesses have chosen these techniques to penetrate into market. These days, there are literally various factors influencing new advertisement techniques and it is important to detect the effect of them using different methods such as factor analysis. Azad et al. (2013a), for instance, presented a study to detect important factors influencing brand identification using factor analysis. They reported five factors including sense of brand, brand community, trust to brand, value of brand and personality of brand. Azad et al. (2013b), in other study, found important factors influencing on food market using factor analysis. They stated six major factors including brand loyalty, physical characteristics, pricing effects, performance characteristics, brand relationship and brand position influence food industry, significantly.

* Corresponding author.

E-mail addresses: dr.naserazad@yahoo.com (N. Azad)

(C) 2013 Growing Science Ltd. All rights reserved.

doi: $10.5267 /$ j.uscm.2013.09.001 
Patsioura et al. (2009) presented an effectiveness conceptual framework to make an assessment on the overall performance of corporate advertising web sites towards the multiple advertising, promotional and relationship marketing goals of their establishment. More specifically, communication, feedback and customer support policies were tested to detect their contribution in generating or affecting advertising "effects". Their findings disclosed significant dimensions of the participants' behavior based on their actions, activities, preferences and intentions. In addition, the outcomes demonstrate a big impact of the relationship marketing qualitative factors in question on specific advertising effectiveness indicators.

Jung et al. (2009) investigated an important exception to the "value congruity hypothesis," which exists that advertising could be more effective when it were congruent with cultural values. The survey presented a paradoxical "reverse authority effect" among young adult consumers in traditionally high power distance (PD) countries. The results stated a reverse authority impact in Korea and attenuation of this impact in the USA in the first study. In addition, the second study demonstrated a reverse authority impact in Thailand, implying the generality of the impact across young consumers in traditionally high PD countries. They stated that a shift away from traditional cultural values had appeared in the course of modernization, as Western ideology gained popularity among young adult consumers in Eastern countries.

Deane and Pathak (2009) examined a new online advertisement targeting method, which adapts and utilizes various powerful and well examined information retrieval and lexical methods to develop an estimate of a user's affinity for particular products and services based on an analysis of a user's web surfing behavior.

The development of mobile services has made breakthrough advances during the past two decades. Like Internet services, mobile telecommunications exists anywhere, anytime and always online characteristics. As growth in the Internet advertising market goes on, mobile advertising has absorbed much attention. Patrick Rau and Chen (2006) studied the effectiveness of two kinds of mobile message advertisements, watermarks and music. They performed two experiments to examine four proposed hypotheses. In this survey, the independent variable in experiment 1 was the watermark transparency $(20 \%, 40 \%$ and $60 \%)$. The independent variable in experiment 2 was the music format including five levels: no music, vocal and instrumental version at high volume, vocal and instrumental version at low volume, instrumental version at high volume and instrumental version at low volume. The results stated that the watermarks transparency and format were effective in mobile advertising. Music and vocal/instrumental music versions were found useful in mobile advertisements. The vocal music version was detected effective in mobile advertising.

Nettelhorst and Brannon (2012) evaluated the impact of advertisement choice on individuals' subsequent intention towards the advertisement. People who took part in this survey decided which kind of advertisement to watch or they were not given a choice. They reported that advertisement choice substantially impacted female participants' subsequent attention towards the advertisement but not males'. This effect implied that this marketing method should be implemented in specific situations to target women predominately.

According to Kao et al. (2012), an increasing number of users apply cell phones daily and they are not only wish to make phone calls, but can also implement various applications on their mobile phones. When installing mobile applications, developers normally face with the cross-platform incompatibility problem. In addition, because mobile Web browsers have supported more and more Web-related standards, Web applications are more possible to be executed on various platforms than mobile apps. Kao et al. (2012) proposed a Web-based platform for applying applications on mobile devices, which provides various services for developers such as offline service, content adaptation service, and synchronization service. 


\section{The proposed model}

This paper presents an empirical investigation to find the effect of new advertisement techniques on export based product development in a case study of mobile devices. The proposed study designs a questionnaire in Likert scale consists of 29 questions, distributes it among 150 exporters of mobile devices in Iran. Cronbach alpha is calculated as 0.826. In addition, Kaiser-Meyer-Olkin Measure of Sampling Adequacy and Approx. Chi-Square are 0.790 and 1023.3, respectively. We first investigate some basic statistics to make sure there is no need to remove any questions. Table 1 summarizes the summary of our results.

\section{Table 1}

The summary of basic statistics

\begin{tabular}{|c|c|c|c|c|c|c|c|c|}
\hline & \multirow{2}{*}{$\begin{array}{c}\mathrm{N} \\
\text { Statistic }\end{array}$} & \multirow{2}{*}{$\begin{array}{l}\text { Range } \\
\text { Statistic }\end{array}$} & \multirow{2}{*}{$\begin{array}{l}\text { Minimum } \\
\text { Statistic }\end{array}$} & \multirow{2}{*}{$\begin{array}{l}\text { Maximum } \\
\text { Statistic }\end{array}$} & \multicolumn{2}{|c|}{ Skewness } & \multicolumn{2}{|c|}{ Kurtosis } \\
\hline & & & & & Statistic & Std. Error & Statistic & Statistic \\
\hline Customer friendly & 193 & 3.00 & 2.00 & 5.00 & -.920 & .175 & .776 & .348 \\
\hline Advertising Language & 193 & 4.00 & 1.00 & 5.00 & -.650 & 175 & .354 & .348 \\
\hline Potential customers & 193 & 4.00 & 1.00 & 5.00 & -.558 & .175 & .273 & .348 \\
\hline Ongoing promotions & 193 & 3.00 & 2.00 & 5.00 & -.231 & .175 & -.539 & .348 \\
\hline Leading market share & 193 & 4.00 & 1.00 & 5.00 & -.311 & .175 & -.365 & .348 \\
\hline Monopoly position & 193 & 4.00 & 1.00 & 5.00 & -.614 & .175 & -.240 & .348 \\
\hline Commodity production Favorites & 193 & 3.00 & 2.00 & 5.00 & -.868 & .175 & -.187 & .348 \\
\hline Customer Loyalty & 193 & 4.00 & 1.00 & 5.00 & -.460 & .175 & -.411 & 348 \\
\hline Brand Personality & 193 & 4.00 & 1.00 & 5.00 & -.682 & .175 & .175 & .348 \\
\hline Too much negative publicity & 193 & 4.00 & 1.00 & 5.00 & -.148 & 175 & -.115 & .348 \\
\hline Social values & 193 & 4.00 & 1.00 & 5.00 & -.486 & .175 & .684 & .348 \\
\hline Advertising Strategy & 193 & 4.00 & 1.00 & 5.00 & -.667 & .175 & .855 & 348 \\
\hline Dynamic Advertising & 193 & 4.00 & 1.00 & 5.00 & -.777 & 175 & .612 & .348 \\
\hline Traditional media & 193 & 4.00 & 1.00 & 5.00 & -.287 & 175 & -.459 & .348 \\
\hline Outdoor Advertising & 193 & 4.00 & 1.00 & 5.00 & -.254 & .175 & -.176 & .348 \\
\hline Advertising by mail & 193 & 4.00 & 1.00 & 5.00 & .016 & .175 & -.508 & .348 \\
\hline New Media & 193 & 4.00 & 1.00 & 5.00 & -.183 & .175 & -.750 & .348 \\
\hline Customer demand & 193 & 4.00 & 1.00 & 5.00 & -.341 & 175 & .068 & .348 \\
\hline The way of introducing a product & 193 & 4.00 & 1.00 & 5.00 & -.662 & 175 & .735 & .348 \\
\hline Pricing decisions & 193 & 3.00 & 2.00 & 5.00 & -.674 & .175 & -.309 & .348 \\
\hline Growth rate of sales & 193 & 3.00 & 2.00 & 5.00 & -.040 & 175 & -.631 & .348 \\
\hline Potential customers & 193 & 3.00 & 2.00 & 5.00 & -.098 & .175 & -.712 & .348 \\
\hline Unaware customers & 193 & 3.00 & 2.00 & 5.00 & .027 & .175 & -.840 & .348 \\
\hline Customers buyer & 193 & 4.00 & 1.00 & 5.00 & -.271 & .175 & -.410 & .348 \\
\hline Product Life Cycle & 192 & 3.00 & 2.00 & 5.00 & .136 & .175 & -.786 & .349 \\
\hline Feedback Marketing Strategies & 193 & 3.00 & 2.00 & 5.00 & -.229 & .175 & -.509 & .348 \\
\hline Valid N (listwise) & 192 & & & & & & & \\
\hline
\end{tabular}

The results of Table 1 clearly show that all skewness values are within acceptable limits, which means we do not need to remove any questions from the survey. Table 2 presents details of principal component analysis.

Table 2

The summary of principal component analysis

\begin{tabular}{|c|c|c|c|c|c|c|c|c|c|}
\hline \multirow{3}{*}{ Component } & \multicolumn{9}{|c|}{ Total Variance Explained } \\
\hline & \multicolumn{3}{|c|}{ Initial Eigenvalues } & \multicolumn{3}{|c|}{ Extraction Sums of Squared Loadings } & \multicolumn{3}{|c|}{ Rotation Sums of Squared Loadings } \\
\hline & Total & $\%$ of Variance & $\%$ Cumulative & Total & $\%$ of Variance & $\%$ Cumulative & Total & $\%$ of Variance & $\%$ Cumulative \\
\hline 1 & 5.113 & 19.665 & 19.665 & 5.113 & 19.665 & 19.665 & 2.368 & 9.107 & 9.107 \\
\hline 2 & 2.019 & 7.767 & 27.432 & 2.019 & 7.767 & 27.432 & 2.093 & 8.051 & 17.158 \\
\hline 3 & 1.575 & 6.056 & 33.489 & 1.575 & 6.056 & 33.489 & 2.084 & 8.014 & 25.172 \\
\hline 4 & 1.330 & 5.114 & 38.603 & 1.330 & 5.114 & 38.603 & 1.679 & 6.459 & 31.631 \\
\hline 5 & 1.257 & 4.834 & 43.437 & 1.257 & 4.834 & 43.437 & 1.646 & 6.330 & 37.961 \\
\hline 6 & 1.216 & 4.676 & 48.112 & 1.216 & 4.676 & 48.112 & 1.626 & 6.253 & 44.214 \\
\hline 7 & 1.077 & 4.141 & 52.253 & 1.077 & 4.141 & 52.253 & 1.564 & 6.014 & 50.229 \\
\hline 8 & 1.062 & 4.083 & 56.337 & 1.062 & 4.083 & 56.337 & 1.299 & 4.995 & 55.224 \\
\hline 9 & 1.007 & 3.874 & 60.211 & 1.007 & 3.874 & 60.211 & 1.297 & 4.987 & 60.211 \\
\hline 10 & .945 & 3.636 & 63.847 & & & & & & \\
\hline 11 & .878 & 3.377 & 67.224 & & & & & & \\
\hline 12 & .862 & 3.315 & 70.539 & & & & & & \\
\hline 13 & .810 & 3.116 & 73.654 & & & & & & \\
\hline 14 & .756 & 2.909 & 76.564 & & & & & & \\
\hline 15 & .729 & 2.803 & 79.367 & & & & & & \\
\hline 16 & .657 & 2.528 & 81.895 & & & & & & \\
\hline 17 & .595 & 2.289 & 84.184 & & & & & & \\
\hline 18 & .566 & 2.178 & 86.362 & & & & & & \\
\hline 19 & .555 & 2.133 & 88.495 & & & & & & \\
\hline 20 & .515 & 1.982 & 90.478 & & & & & & \\
\hline 21 & .492 & 1.891 & 92.369 & & & & & & \\
\hline 22 & .457 & 1.756 & 94.125 & & & & & & \\
\hline 23 & . 444 & 1.709 & 95.834 & & & & & & \\
\hline 24 & .392 & 1.507 & 97.341 & & & & & & \\
\hline 25 & .378 & 1.453 & 98.794 & & & & & & \\
\hline 26 & .314 & 1.206 & 100.000 & & & & & & \\
\hline
\end{tabular}


In addition, Fig. 1 shows Scree plot of the information and based on the results of Table 2 and Fig. 1 we can conclude that there are five factors associated with the proposed study of this paper. The study uses Varimax method as desirable rotation and Table 3 demonstrates the results of our survey.

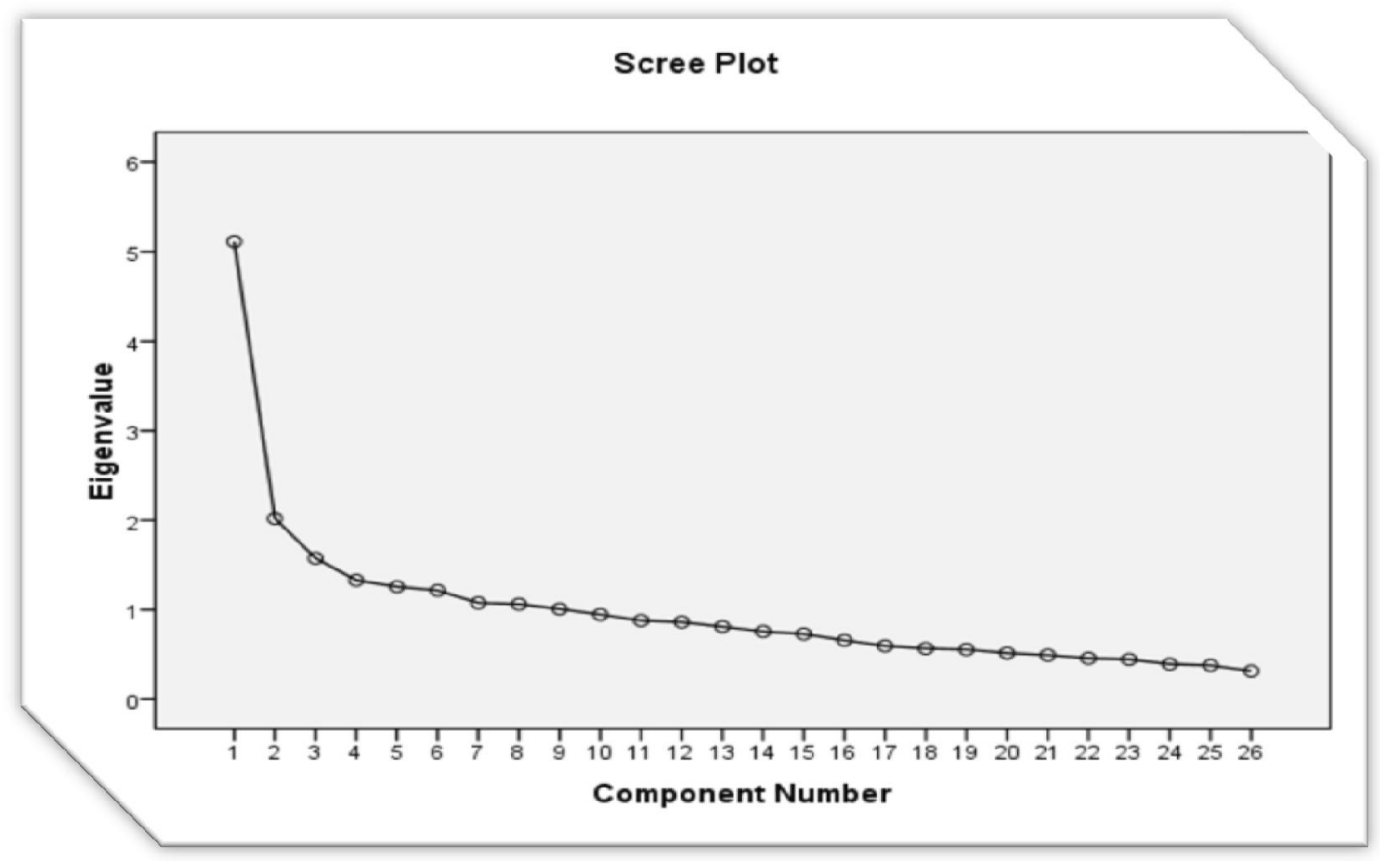

Fig. 1. The summary of Scree ploy

Table 3

The summary of principal component analysis after rotation

\begin{tabular}{|c|c|c|c|c|c|c|c|c|c|}
\hline & \multicolumn{9}{|c|}{ Factors } \\
\hline & 1 & 2 & 3 & 4 & 5 & 6 & 7 & 8 & 9 \\
\hline New Media & .772 & & & & & & & & \\
\hline Advertising by mail & .752 & & & & & & & & \\
\hline Outdoor Advertising & .566 & & & & & & & .398 & \\
\hline Too much negative publicity & .551 & & & & & & & -.342 & \\
\hline Advertising Language & .475 & & & & & .335 & .436 & & \\
\hline Pricing decisions & & .705 & & & & & & & \\
\hline Customer demand & & .683 & & & & & & & \\
\hline The way of introducing a product & & .539 & & & & .363 & & & \\
\hline Growth rate of sales & & .391 & & & & & & & \\
\hline Customer Loyalty & & & .737 & & & & & & \\
\hline Brand Personality & & & .728 & & & & & & \\
\hline Social values & & & .507 & & & & & & \\
\hline Unaware customers & & & & .723 & & & & & \\
\hline Potential customers & & & & .711 & & & & & \\
\hline Buyer customer & & .436 & & .449 & & & .354 & & \\
\hline Ongoing promotions & & & & & .782 & & & & \\
\hline Dynamic Advertising & & & .334 & & .560 & & & & \\
\hline Product Life Cycle & & .341 & & & .469 & & & & \\
\hline Advertising Strategy & & & & & & .662 & & & \\
\hline Feedback Marketing Strategies & & & & & & .660 & & & \\
\hline Customer friendly & & & & & & & .676 & & \\
\hline Monopoly position & & & & & & & .596 & & \\
\hline Traditional media & & & .414 & & & & & .580 & \\
\hline Commodity production Favorites & & & & & .381 & & & .431 & \\
\hline Competitors & & & & & & & & & .722 \\
\hline Leading market share & & & & & & & & & .570 \\
\hline
\end{tabular}

Based on the results of Table 3, we have derived five factors including emotional effects, brand promises, pricing strategy, modern advertisements and detected promotions. Table 4 shows details of our findings on non-standard components. 
Table 4

The summary of factors extracted

\begin{tabular}{|c|c|c|c|}
\hline Row & Factor (Importance) & Variable & Important coefficient \\
\hline \multirow{3}{*}{1} & \multirow{3}{*}{ Modern Advertising (0.50) } & New Media & 0.63 \\
\hline & & Advertising by mail & 0.72 \\
\hline & & Outdoor Advertising & 0.51 \\
\hline \multirow{4}{*}{2} & \multirow{4}{*}{ Pricing Strategies $(0.58)$} & Pricing decisions & 0.61 \\
\hline & & Customer demand & 0.47 \\
\hline & & Growth rate of sales & 0.46 \\
\hline & & The way of introducing a product & 0.65 \\
\hline \multirow{3}{*}{3} & \multirow{3}{*}{ Brand Promise (0.59) } & Customer Loyalty & 0.72 \\
\hline & & Brand Personality & 0.77 \\
\hline & & Social values & 0.44 \\
\hline \multirow{3}{*}{4} & \multirow{3}{*}{ Emotional Impact (0.91) } & Unaware customers & 0.59 \\
\hline & & Potential customers & 0.71 \\
\hline & & Buyer customers & 0.29 \\
\hline
\end{tabular}

Based on the results of Table 4, the relative importance of four factors including modern advertising, pricing strategies, brand promises and emotional impact are $0.50,0.58,0.59$ and 0.91 , respectively. Modern advertisement is the first factor in our investigation, which includes new media, advertising by mail and outdoor advertising. The second factor, pricing strategies, consists of four factors including pricing decisions, customer demand, growth rate of sales and the way of introducing a product. Brand promise is the third factor including customer loyalty, brand personality and social values. Finally, emotional impact is the last factor, which includes three factors. This factor includes unaware customers, potential customers as well as buyer customers.

\section{Conclusion}

During the past few years, there have been tremendous changes on advertisement techniques such as email messages, short mobile services, etc. These services normally do not cost significantly and may have pleasant outcomes. In this paper, we have presented a survey to detect influencing factors on developing export based products in mobile industry. The study designed a questionnaire and distributed among randomly selected experts who were involved in this industry and using factor analysis extracted important factors. The results of our survey have detected different factors such as modern advertising, pricing strategies, brand promises and emotional impact, which influence on product development in mobile industry. Based on the results of our survey, we have found out that email message is one of the most successful factors for penetrating into market and absorbing new potential customers.

\section{Acknowledgment}

The authors would like to thank anonymous referees for constructive comments on earlier version of this work.

\section{References}

Azad, N., Seyedaliakbar, S.M., Hosseinzadeh, A., \& Arabi, A. (2013a). An exploration study on factors influencing Iranian food industry. Management Science Letters, 3(5), 1315-1322.

Azad, N., Raoof, D., Haj Seyed Javadi, S., Asgari, H., \& Bagheri, H. (2013b). An exploration study to find important factors influencing on brand identification. Management Science Letters, 3(9), 2425-2430.

Deane, J., \& Pathak, P. (2009). Ontological analysis of web surf history to maximize the clickthrough probability of web advertisements. Decision Support Systems, 47(4), 364-373.

Jung, J. M., Polyorat, K., \& Kellaris, J. J. (2009). A cultural paradox in authority-based advertising. International Marketing Review, 26(6), 601-632. 
Kao, Y. W., Lin, C., Yang, K. A., \& Yuan, S. M. (2012). A Web-based, Offline-able, and Personalized Runtime Environment for executing applications on mobile devices. Computer Standards \& Interfaces, 34(1), 212-224.

Lee, T. D., Chung, W., \& Taylor, R. E. (2011). A strategic response to the financial crisis: an empirical analysis of financial services advertising before and during the financial crisis. Journal of Services Marketing, 25(3), 150-164.

Nettelhorst, S. C., \& Brannon, L. A. (2012). The effect of advertisement choice on attention. Computers in Human Behavior, 28(2), 683-687.

Patrick Rau, P. L., \& Chen, D. (2006). Effects of watermark and music on mobile message advertisements. International journal of human-computer studies, 64(9), 905-914.

Patsioura, F., Vlachopoulou, M., \& Manthou, V. (2009). A new advertising effectiveness model for corporate advertising web sites: A relationship marketing approach. Benchmarking: An International Journal, 16(3), 372-386. 